Lutkovskyi Ruslan. Quality of life of patients with surgical treatment of abdominal hernias. Journal of Education, Health and Sport. 2020;10(12):118-124. eISSN 2391-8306. DOI http://dx.doi.org/10.12775/JEHS.2020.10.12.011 https://apcz.umk.pl/czasopisma/index.php/JEHS/article/view/JEHS.2020.10.12.011

https://zenodo.org/record/4321294

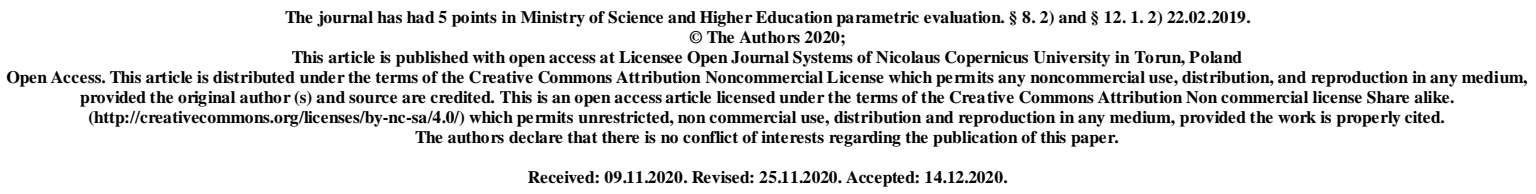

UDK: 616-007.43-089:008.1

\title{
Quality of life of patients with surgical treatment of abdominal hernias
}

\section{Ruslan Lutkovskyi}

\author{
Vinnitsa National Pirogov Memorial Medical University, Ukraine \\ Ph.D., Associate Professor, Department of General Surgery
}

\begin{abstract}
Aim - to analyze the quality of life (QOL) of patients in the surgical treatment of abdominal hernias using nanomodified polypropylene mesh.

Materials and methods. An analysis of the quality of life of patients in the surgical treatment of abdominal hernias for the period from 2015 to 2020.700 patients with abdominal hernias aged 30 to 75 years in which performed alloplasty. There were 386 women $(55.1 \%)$ and 314 men (44.9\%). Concomitant pathology was detected in $85.6 \%$ of patients. It should be noted that the majority $(64.8 \%)$ had cardiovascular pathology and 80 patients suffered from grade II - III alimentary obesity.

Results and discussion. The results of surgical treatment of abdominal hernias in patients of the main group and the comparison group were evaluated by analyzing the quality of life according to the SF - 36 questionnaire.

The difference in quality of life in patients of the main group a year after hernioplasty compared with those in hospitalization, statistically significant $(\mathrm{P}<0,01)$. The rate of FF increased 1.2 times compared with hospitalization, RF 1.8 times, PF - 1.1 times, GH - 1.4 times, VA - 1.7 times, SF - 1.9 times, RA - 3.1 times, $\mathrm{MH}-1.6$ times. The quality of life index (QLI) increased by $59.6 \%$ compared to the initial one, ie by more than half.
\end{abstract}


The difference in quality of life in patients of the main group 2 years after hernioplasty compared with those in hospitalization, statistically significant $(\mathrm{P}<0,01)$. The index of FF increased 1.7 times compared with the indicator at hospitalization, RF 2.5 times, PF - 1.5 times, GH - 2.0 times, VA - 2.2 times, SF - 2.4 times, RA - 4.1 times, $\mathrm{MH}-1.8$ times. The quality of life index (QLI) increased by $109.2 \%$ compared to the initial one, ie by more than half.

When comparing the QOL at hospitalization and after 24 months. after hernioplasty in patients of the comparison group not only there is no significant difference in the indicators of FF, RF, PF, GH, SF and VA, but it should be noted that the indicators of MH and RA, which had a negative dynamics, the quality of life of patients in the comparison group even deteriorated. QLI increased by $10.0 \%$ compared with hospitalization. The difference in quality of life in patients of the comparison group at hospitalization and after 24 months. after surgery did not reach the level of statistical significance $(\mathrm{P}<0,001)$.

The difference in QLI in patients of the main group after 24 months. after hernioplasty compared with this indicator of QLI in patients of the comparison group is statistically significant $(\mathrm{P}<0,05)$.

Conclusions. It was found that in patients who were implanted during surgery with a nanomodified mesh implant with the antiseptic polyhexamethylene guanidine chloride QLI was 2.1 times higher than in hospitalization and 1.8 times higher than in patients of the comparison group. Therefore, it is possible to recognize the effectiveness of surgical treatment of abdominal hernias using nanomodified polypropylene mesh made of polyhexamethylene guanidine chloride, given the indicators of QOL in the postoperative period.

Key words: abdominal hernia; nanomodified polypropylene mesh; postoperative wound complications; quality of life.

Introduction. We compared the quality of life of patients with abdominal hernias. The quality of life (QOL) of patients was studied using the questionnaire The MOS 36- ItemShort - Form Health Survey (SF - 36), which allows you to assess QOL in points on the following signs of health (HE): physical functioning (FF), pain factor BF), mental health (PZ), general health (ZZ), role functioning (RF), vital activity (WA), social functioning (SF), role activity (RD).

Aim - to analyze the quality of life (QOL) of patients in the surgical treatment of abdominal hernias using nanomodified polypropylene mesh. 


\section{Materials and methods}

An analysis of the quality of life of patients in the surgical treatment of abdominal hernias for the period from 2015 to 2020.700 patients with abdominal hernias aged 30 to 75 years in which performed alloplasty. There were 386 women (55.1\%) and 314 men (44.9\%). Concomitant pathology was detected in $85.6 \%$ of patients. It should be noted that the majority (64.8\%) had cardiovascular pathology and 80 patients suffered from grade II - III alimentary obesity.

All patients on an outpatient basis on average during (10.0 \pm 3.4$)$ days underwent special preoperative training $[5,6]$, which included: 1) increasing reserves of cardiopulmonary activity, 2) corrective therapy of comorbidities, 3) prevention of thromboembolic complications, 4) prevention of infectious complications from the postoperative wound, 5) maximum bowel cleansing. To cleanse the intestines and reduce their volume, patients were recommended a slag-free diet with the exception of bread, flour and potato dishes, and prescribed laxatives ("Regulax", "Duphalac") and cleansing enemas. In this way, it is possible to achieve maximum cleansing and reduction of bowel volume and hernial protrusion, as well as weight loss. In some patients, intractable hernias became intractable. On the eve of surgery, 12 hours before surgery, Fortrans was prescribed according to the scheme. The effectiveness of preoperative preparation was monitored by monitoring the function of the cardiovascular system and the function of external respiration. Antibacterial prophylaxis was performed using generation III cephalosporins (cefosulbin) in combination with metronidazole. In order to prevent pulmonary embolism, low molecular weight heparins were used, as well as compression underwear for the lower extremities during surgery and for 1 month in the postoperative period. Depending on the use of the type of mesh implant, patients were divided into two groups, which were comparable in age, sex ratio and size of abdominal hernias.

In $350(50 \%)$ patients of the main group used nanomodified polypropylene mesh implant [1 - 4]. In the comparison group, 350 (50\%) patients used a classic polypropylene mesh implant. In the early postoperative period, treatment measures included the correction of disorders of the cardiovascular and respiratory systems, stimulation of intestinal function. All patients were given Dicloberl $3 \mathrm{ml}$ intramuscularly for 7 days after surgery to reduce the inflammatory response of the abdominal wall to mesh implantation. In order to prevent stress ulcers of the gastrointestinal tract was prescribed "Kvamatel" according to the scheme. Antibacterial therapy with cefosulbin $1 \mathrm{~g}$ twice daily was continued in all patients, as they all 
had an increased risk of infectious complications from the wound. In order to prevent pulmonary embolism, low molecular weight heparins were used for 7 to 9 days.

\section{Results and discussion}

The results of surgical treatment of abdominal hernias in patients of the main group and the comparison group were evaluated by analyzing the quality of life according to the SF - 36 questionnaire.

Indicators of QOL of the main group and the comparison group in 1 - 2 years after surgical treatment of abdominal hernia are shown in table 1 - 3 and are clearly represented by the diagram (Figure 1).

Table 1 - Comparative characteristics of quality of life in patients of the main group at hospitalization and after 12 months. after SF-36 hernioplasty

\begin{tabular}{|c|c|c|c|c|}
\hline \multicolumn{2}{|c|}{} & $\begin{array}{c}\text { At hospitalization, } \\
\text { points }\end{array}$ & $\begin{array}{c}\text { After 12 months, } \\
\text { points }\end{array}$ & P \\
\hline \multirow{3}{*}{ Physical } & FF & $54,2 \pm 2,6$ & $65,7 \pm 2,1$ & 0,002 \\
\cline { 2 - 5 } & RF & $37,3 \pm 4,5$ & $68,9 \pm 3,0$ & 0,002 \\
\cline { 2 - 5 } & PF & $58,6 \pm 2,3$ & $64,6 \pm 2,1$ & 0,001 \\
\cline { 2 - 5 } & GH & $34,5 \pm 2,4$ & $50 \pm 2,0$ & 0,002 \\
\hline \multirow{3}{*}{ Psychological } & VA & $35,9 \pm 1,7$ & $61,1 \pm 1,2$ & 0,001 \\
\cline { 2 - 5 } & SF & $37,1 \pm 2,1$ & $69,1 \pm 1,8$ & 0,002 \\
\cline { 2 - 5 } & RA & $22,3 \pm 4,2$ & $68,7 \pm 3,3$ & 0,001 \\
\cline { 2 - 5 } & MH & $42,2 \pm 1,4$ & $65,6 \pm 1,1$ & 0,002 \\
\hline Quality of life index & & $40,31 \pm 2,6$ & $64,31 \pm 4,3$ & 0,001 \\
\hline
\end{tabular}

Note. The difference in performance is significant at $\mathrm{P}<0,01$

Table 2 - Comparative characteristics of quality of life in patients of the main group at hospitalization and after 24 months. after SF-36 hernioplasty

\begin{tabular}{|c|c|c|c|c|}
\hline \multicolumn{2}{|c|}{} & $\begin{array}{c}\text { At hospitalization, } \\
\text { points }\end{array}$ & $\begin{array}{c}\text { After 24 months, } \\
\text { points }\end{array}$ & P \\
\hline \multirow{3}{*}{ Physical } & FF & $54,2 \pm 2,7$ & $90,8 \pm 2,4$ & 0,002 \\
\cline { 2 - 5 } & RF & $37,3 \pm 4,6$ & $92,4 \pm 3,0$ & 0,002 \\
\cline { 2 - 5 } & PF & $58,8 \pm 2,2$ & $89,2 \pm 2,0$ & 0,001 \\
\cline { 2 - 5 } & GH & $34,7 \pm 2,3$ & $70 \pm 2,0$ & 0,002 \\
\hline \multirow{3}{*}{ Psychological } & VA & $35,9 \pm 1,6$ & $77,8 \pm 1,3$ & 0,001 \\
\cline { 2 - 5 } & SF & $37,2 \pm 2,3$ & $89,2 \pm 1,9$ & 0,002 \\
\cline { 2 - 5 } & RA & $22,1 \pm 4,4$ & $89,8 \pm 3,1$ & 0,001 \\
\cline { 2 - 5 } & MH & $42,3 \pm 1,6$ & $75,3 \pm 1,3$ & 0,002 \\
\hline Quality of life index & & $40,31 \pm 2,6$ & $84,31 \pm 4,1$ & 0,001 \\
\hline
\end{tabular}

Note. The difference in performance is significant at $\mathrm{P}<0,01$ 
Table 3 - Comparative characteristics of quality of life indicators in patients of the comparison group at hospitalization and after 24 months after SF-36 hernioplasty

\begin{tabular}{|c|c|c|c|c|}
\hline \multicolumn{2}{|c}{ HE } & $\begin{array}{c}\text { At hospitalization, } \\
\text { points }\end{array}$ & $\begin{array}{c}\text { After 24 months, } \\
\text { points }\end{array}$ & P \\
\hline \multirow{3}{*}{ Physical } & FF & $47,3 \pm 2,6$ & $56,4 \pm 2,6$ & 0,03 \\
\cline { 2 - 5 } & RF & $41,1 \pm 3,6$ & $61,5 \pm 2,1$ & 0,02 \\
\cline { 2 - 5 } & PF & $63,1 \pm 2,0$ & $65,5 \pm 2,4$ & 0,45 \\
\cline { 2 - 5 } & GH & $45,4 \pm 1,9$ & $42,6 \pm 2,1$ & $-0,25$ \\
\hline \multirow{3}{*}{ Psychological } & VA & $41,1 \pm 1,5$ & $41,1 \pm 1,9$ & 2,13 \\
\cline { 2 - 5 } & SF & $32,9 \pm 1,8$ & $33,7 \pm 1,8$ & 0,63 \\
\cline { 2 - 5 } & RA & $27,7 \pm 3,8$ & $26,1 \pm 3,2$ & $-0,29$ \\
\cline { 2 - 5 } & MH & $40,3 \pm 1,7$ & $49,8 \pm 1,5$ & 0,25 \\
\hline Quality of life index & & $42,36 \pm 3,2$ & $47,09 \pm 3,3$ & 0,13 \\
\hline
\end{tabular}

Note. The difference in performance is significant at $\mathrm{P}<0,01$.

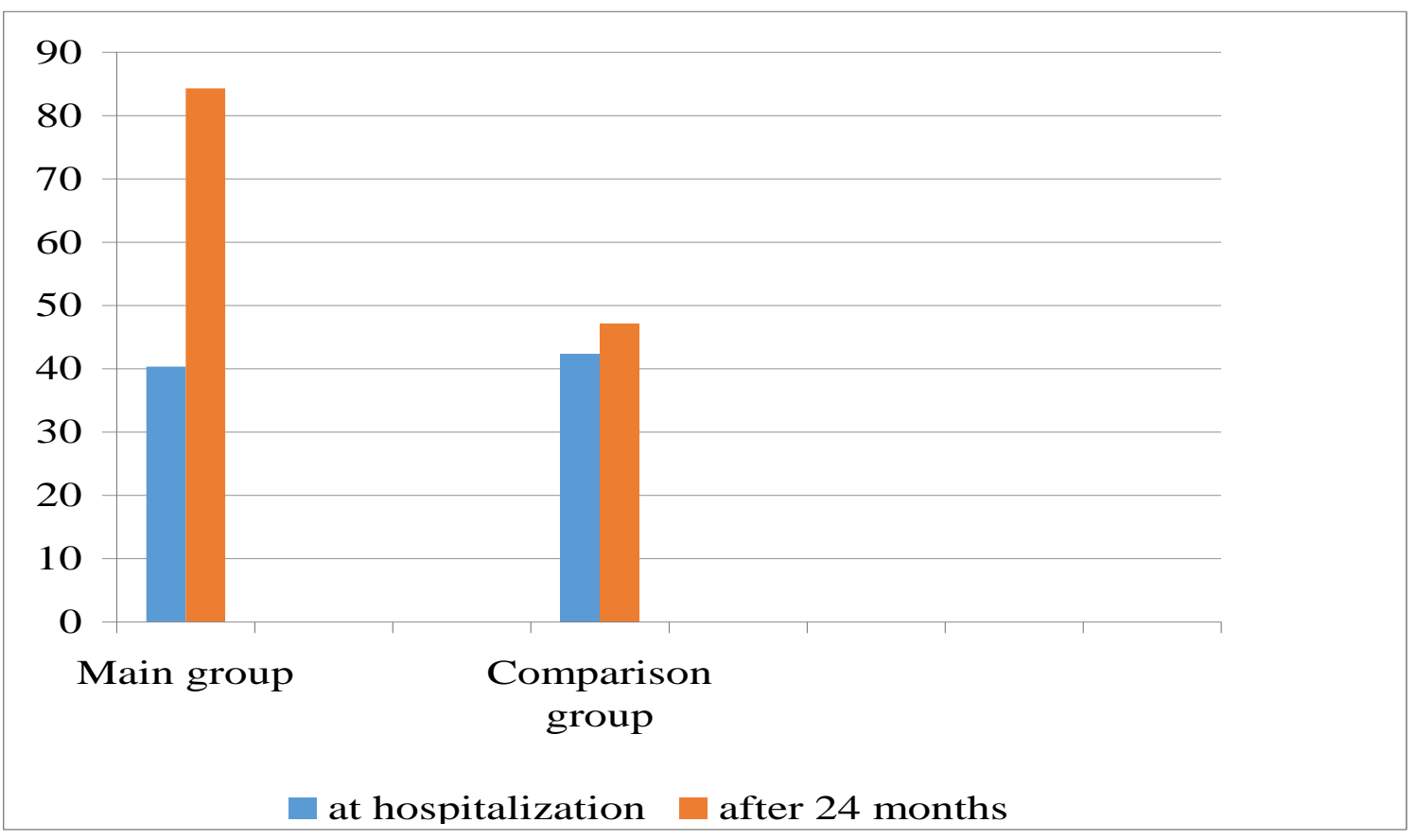

Figure 1 - Characteristics of QLI in patients of the study group at hospitalization and after 24 months, after hernioplasty

The difference in quality of life in patients of the main group a year after hernioplasty compared with those in hospitalization, statistically significant $(\mathrm{P}<0,01)$. The rate of FF increased 1.2 times compared with hospitalization, RF 1.8 times, PF - 1.1 times, GH - 1.4 times, VA - 1.7 times, SF - 1.9 times, RA - 3.1 times, MH - 1.6 times. The quality of life index (QLI) increased by $59.6 \%$ compared to the initial one, ie by more than half. 
The difference in quality of life in patients of the main group 2 years after hernioplasty compared with those in hospitalization, statistically significant $(\mathrm{P}<0,01)$. The index of FF increased 1.7 times compared with the indicator at hospitalization, RF 2.5 times, PF - 1.5 times, GH - 2.0 times, VA - 2.2 times, SF - 2.4 times, RA - 4.1 times, $\mathrm{MH}-1.8$ times. The quality of life index (QLI) increased by $109.2 \%$ compared to the initial one, ie by more than half.

When comparing the QOL at hospitalization and after 24 months. after hernioplasty in patients of the comparison group not only there is no significant difference in the indicators of FF, RF, PF, GH, SF and VA, but it should be noted that the indicators of MH and RA, which had a negative dynamics, the quality of life of patients in the comparison group even deteriorated. QLI increased by $10.0 \%$ compared with hospitalization. The difference in quality of life in patients of the comparison group at hospitalization and after 24 months. after surgery did not reach the level of statistical significance $(\mathrm{P}<0,001)$.

The difference in QLI in patients of the main group after 24 months. after hernioplasty compared with this indicator of QLI in patients of the comparison group is statistically significant $(\mathrm{P}<0,05)$. The ratio of QLI in patients of the study group at hospitalization and after 24 months. after hernioplasty is clearly shown in the diagram (Figure 1).

\section{Conclusions}

It was found that in patients who were implanted during surgery with a nanomodified mesh implant with the antiseptic polyhexamethylene guanidine chloride QLI was 2.1 times higher than in hospitalization and 1.8 times higher than in patients of the comparison group. Therefore, it is possible to recognize the effectiveness of surgical treatment of abdominal hernias using nanomodified polypropylene mesh made of polyhexamethylene guanidine chloride, given the indicators of QOL in the postoperative period.

\section{Refferences}

1. Bendik N.I., Rucavzev G.I. (2003) Zastosuvannja vitchusnjanoi chirurgichnoi polipropilenovoi sitku [Application of domestic surgical polypropylene mesh]. Kyiv: Klinichna chirurgia, 11, 8 [in Ukrainian].

2. Lutkovskyi R.A. (2019) Operativne likuvannja pisljaoperacijnich grig givota velikogo rosmiru pri vikoristanni polipropilenovoi sitki modifikovanoi vuglezevumi nanotrubkami ta antisepticom [Surgical treatment of largesized postoperative abdominal hernias using polypropylene mesh modified with carbon nanotubes and antiseptic]. Poltava: Visnik problem biologii i medicine, 1, 167-170 [in Ukrainian]. 
3. Lutkovskyi R.A. (2017) Reakcija tkanin na polipropilenovi sitchasti implantati [Response of tissues to polypropylene mesh implants]. Vinnica: Visnik morfologii, 2, 295299 [in Ukrainian].

4. Lutkovskyi RA, Feleshtynskiy JP, Viltsanuk OA, Rezanova NM, vinachidniki. Vinnuckuj nazionalnuj medichnij universitet imeni M.I.Pirogova patentovlasnik. Sposib aloplastiki pisljaoperazijnuch ventralnich grug $\mathrm{s}$ vikoristannjam nanomodifikovanoi polipropilenovoi sitku. Patent Ukrainu na korusnu model №132818. 2019 Ver 11. [inUkrainian].

5. Feleschtinskij J.P.(2012) Pisljaoperacijni grigi givota [Postoperative abdominal hernias]. Kyiv: TOV «Bisnes-Logika» [in Ukrainian].

6. Millbourn D., Cengiz Y., Israelsson L.A. Risk factors for wound complications in midline abdominal incisions related to the size of stitches // Hernia. - 2011. - Vol. 15. - P. $261-266$. 